\title{
EFEKTIVITAS SERBUK GERGAJI SEBAGAI CAMPURAN MEDIA PADA REMEDLASI LAHAN TERCEMAR LUMPUR MINYAK BUMI
}

\author{
Tri Retno Dyah L* dan Arief Adhari \\ ${ }^{3}$ Bidang Industri dan Lingkungan - Pusat Aplikasi Isotop dan Radiasi (PAIR) \\ Badan Tenaga Nuklir Nasional (BATAN) \\ Jln. Lebak Bulus Raya No.49 Jakarta 12440 \\ Telp 021-7690709, Fax 021-7691607 \\ cmail : tretno@batan.go.id
}

\section{ABSTRACT \\ Effectiveness of Sandust as Miature of Media on Remediation of Oil Sludge Contaminated Soil}

\begin{abstract}
This study atmed to determine the effectiveness the media mixare of sawdust and rastictual shidge biogus enriched by finctional microorgunism to degrule petroleum siudge. Compost was sterilited by asing 7 ray irradiation with a dose of $25 \mathrm{KGy}$ which was used as carmer in production inoculant microbial (MO). Variation of shadge treatment used was $20 \mathrm{~s}$ otl, $5 \%$ NPK, she addition of M (inoculants microbial) and without $M \mathrm{M}$, soll were $30 \%, 50 \%$ and $50 \%$, sondist were $0 \%, 10 \%, 20 \%$ and $30 \%$, biogas sludge were $0 \%$, $10 \%, 20 \%, 30 \%$ and 4096 ( AO , AI, BO BI, CO, CI, DQ DI, EO, EI, FO, FI). Statistical destgn using CRD (Complesly Rondomized Design) in direv replication with Duncan's fest further. Farameter observations of bioremediation process an 0,30, 60 and 90 days included : temperathere, pH, motsther content, axh content, organic matter content and TPH concentrations. The results showed that the optimal conditians bioremediation of soil contaminated with oil shige was $B$ I composter, which was a compost irradiated-based cunscrtium of micrabial moctalant in a mintare of bulking agent using sawdist $20 \%$, biogas studge $30 \%$ and sotl $30 \%$ ro degrade lydrocurbas in oil siudge 2056 with an efficiency of $83.14 \% \mathrm{IPH}$ degradatian daring 60 days conquosting. The results of the GC-MS analysis shoswed that EI treatment in the trittal distrituation of hydrocarbon C-7 to C-54 in day-60 degraded to hydrocarbons with rantar with C-6 to C-16.
\end{abstract}

Keywords: mirture of media, biaremediation, mitorobid inoculants, degradation, bythocarbons

\section{ABSTRAK}

Penelitian ini bertujuan untuk mengetahui pengaruh efektivitas campuran media serbuk gergaji dan sludge sisu biogas yang diperkaya demgan mikroorganisme fungsional berbasis kormpos inadiasi untuk. mendegradasi lumpur minyak bumi. Kompos disteril menggumakan indiasi sinar- $\gamma$ dengan dosis $25 \mathrm{kGy}$, dgunakan sebagai bahan pernhawa dalam pembuatan mikroba inokulun (IM). Varissi perlakuan yang digumakan adalah lumpur minyak 20\%, NPK $5 \%$, penambahan IM (konsorsium inokulan mikroba) dan tanpa IM, tanah $30 \%, 50 \%$ dan $80 \%$ s sertak gergaji : $0 \%$, $10 \%, 20 \%$ dan $30 \%$, sludge biogas : $0 \%, 10 \%, 20 \%, 30 \%$ dan $40 \%$, ( $\mathrm{A} 0$, $\mathrm{Al}, \mathrm{B} 0, \mathrm{~B} 1, \mathrm{CO}, \mathrm{Cl}, \mathrm{DO}, \mathrm{DI}, \mathrm{EO}, \mathrm{El}, \mathrm{FO}, \mathrm{F1}$ ). Runcangan percobean menggumakan 3 ulangan dengan RAL serta digumakan analisa statistik. ANOVA dengan uji lanjut Dumean. Pengarnatin parameter proses biorematiasi pada. hari ke-0, ke-30, ke-60 dan ke-90 meliputi : suhu, pH, kadar air, kadar abu, kadar bahan orgarik, serta konsentrasi TPH. Hasil penelitian memmjukkan bahwa kondisi optimal bioremediasi lahan tercemir Immpur mitpak adalah composter F1, yakni konsorsium inokulan mikroba berbasis kormpes nadiasi di dalam campuran mediu menggunakan serbuk gergaij $20 \%$ dan sluige biogas sebesar $30 \%$ serta tanah $30 \%$ mampu mendegradasi hidrokarbon dalam ofl siudge scbesar $20 \%$ dengan efisiensi degradasi TPH sebesar 83,1496 selamn 60 hari. Analisis GC-MS pada perlakman E1 menumjukkan bahwa pada hudrokarbon awal distritusi C-7 sampai C-54 sampai hari ke-60 terdegradasi menjadi hidrokation dengan rantar dergan C-6 sampai C-16.

Kata Kunci : camparien media, broremediasi, milorobu fingsional, degradasi, hidrokurbon 


\section{PENDAHULUAN}

Mentrut PP No.85 tahto 1909 ot shudge dikategorikan sebagai limbah B3 (Bahan berbahaya dan Beracun). Oleh karena itu periu dilakukan pengolahan agar tidak mencemari lingkungan. Kandungan terbesar dalam otl sludge adalah petroleum inzirucarón yang dapal dioian dengan proses bioremediasi. Bioremediasi merupakan suatu proses pemulihan (remediasi) lahan yang tercemar limbah organik maupun limbah anorganik dengan memanfaatkan mikroorganisme tungsional. Mikroorganisme tungsional yang berperan adalah mikroba indigenous yaitu mikroba yang hidup di lingkungan tercemar dan mikroba eksogenous yaitu mikroba yang ditambahkan dari luar dan berpotensi tinggi untuk mendegradasi hidrokarbon. Degradasi hidrokarbon berlangsung dalam suasana aerob. Proses bioremediasi tersebut dapat dilakukan secara pengomposan [15]. Selain itu laju biodegradasi dalam proses remediasi tanah tememar dapat ditingkatkan dengan penambahan eampuran media yang dipergunakan untuk memperbaiki permeabilitas, water holding capacity dan porositas untuk meningkatkan laju biodegradasi dalam proses pemulihan [18]. Campman modia isuah icoscoui bafungsi sebagai pengatur porositas, kelembaban, dan sumber nutrisi. Hasil penelitian sebelumnya menunjukkan bahwa pemanfaatan serbuk gergaji sebagai bahan campuran medium tanah dalam bioremediast lahan tercemar hidrokarbon memberikan hasil yang optimal [19].

Kelompok Lingkungan, bidang Industri dan Lingkungan, Pusat Aplikasi Isotop dan Radiasi, PAIR-BATAN telah mengembangkan konsentrat yang berisi kultur mikroba pendegradasi hidrokarbon berbasis kompos iradiasi. Mikroorganisme fungsional yang digunakan adalah konsorsium fungi (F) pendegradasi minyak (Aspergillus niger dan Trichoderma remmim) dan sebagai konsorsia mikroba non-indigenous (B) adalah Bacillus sphaericus, Bacillus cercus dan Pseudomonas aeruginosa yang merupakan hasil isolasi dari Pertambangan minyak Rakyat di Cepu, Jawa Tengah. Penelitian ini bertujuan untuk mengetahui

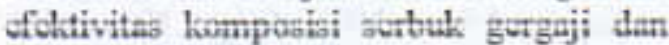
sludge sisa biogas sebagai bahan campuran eampuran media pada proses bioremediasi tahan tercemar oil shudge untuk mengoptimalkan mengoptimalkan \% laju degradasi TPH (Total Petroletam Fijytrocarbons) dan apiikasi nasii remediasi pada tanaman uji.

\section{BAHAN DAN METODA}

\section{Bahan dan Alat}

Bahan yang digunakan adalah : sampel lumpur minyak bumi dari Cepu, sludge sisa biogas yang telah dikomposkan, serbuk gergaji, konsorsium inokulan mikroba pendegradasi hidrokarbon hasil isolasi kelompok Lingkungan PAIR - BATAN, bahan pembawa berupa kompos yang telah diradiasi dengan dosis $25 \mathrm{kGy}$ dan pupuk urea, SP-36 serta $\mathrm{KCl}$ sebagai sumber nutrisi nitrogen dan focfor. Bahan kimia yang digunakan meliputi : larutan buffer, $\mathrm{H}_{2} \mathrm{SO}_{4}$ pekat, n-helssana, selenium mixture merck $10830, \mathrm{NaOH}_{2} \mathrm{H}_{3} \mathrm{BO}_{3}$ dan $\mathrm{HCl} 0,01$ N. Alat yang digunakan terdiri dari wadah/tong (diameter $40 \mathrm{~cm}$ dan tinggi útsui) scibagai compusier isampai pusco bioremediasi secapa pengomposan dan alat-alat laboratorium lainnya(gelas ukur, oven, $\mathrm{pH}$ meter, termometer, tanur dan lainnya).

\section{Metode}

\section{Pembuatan inokulan}

Bahan pembawa berupa kompos sebanyak 9 gr dengan ukuran partikel sekitar $200 \mu \mathrm{m}$ dan kadar air 22,23\% dikemas dalam kantong plastik (polyethylene) dan ditutup rapat dengan sealer. Kemudian disterilkan dengan iradiasi gamma pada dosis 25 kGy [9]. Bahan pembavy ateril tersebont diminakan sebagai media pada pembuatan konsonsia inokulan $\mathrm{F}$ yang terdiri dari Aspergillus nigar, Pseudomonas aeruginosa dan Trichoderma zeanum sedangkan inokulan 
B adalah Bacillus sphaeric dan Bacillus cereus dengan konsentrasi masing masing sekitar $10^{\circ} \mathrm{efu} / \mathrm{g}$. Konsorsia inokulan mikroba indigen (F) dan cksogen (B) tersebut diinkubasi pada suhu $28^{\circ} \mathrm{C}$ selama 14 hari, sebelum digunakan scbagai stimulan Bulking agent dalam bioremediasi lahan tercemar lumpur minyak bumi.

\section{Bioremediasi secara pengomposan}

Konsentrat yang berisi kultur mikroba pendegradasi hidrokarbon berbasis kompos iradiasi tersebut didilusi/diencerkan sampai $10^{7} \mathrm{cfu} / \mathrm{gr}$ dengan penambahan $10 \%$ molasses yang telah dipanaskan, kemudiam dilakukan penggoyangan selama \pm 24 jam. Kultur mikroba dalam bentuk cairan tersebut dicampurkan ke dalam tanah, serbuk gergaji, sludge biogas dan oil shudge serta diberi penambahan NPK sebanyak 5\% dari kandungan ofl shudge (komposisi variasi perlakuan dilihat pada Tabel 1). Kelembaban tanah dijaga sekitar 60 $65 \%$. Semua bahan yang telah dicampur homogen dimasukkan ke dalam Composter yang telah disiapkan. Kemudian dilakukan aerasi dengan pengadukan untuk memberikan suplai oksigen dalam proses bioremediasi. Pengomposan dilakukan dalam Composter selama 90 hari dengan melakukan pengukuran parameter proses : suhu, $\mathrm{pH}$, kadar air, kadar abu, kadar bahan organik (KBO) dan TPH.

Tabel 1. Variasi Perlakuan Penelitian

\begin{tabular}{|c|c|c|c|c|c|}
\hline Perlakuan & $\begin{array}{c}\text { Tanah } \\
(\%)\end{array}$ & $\begin{array}{c}\text { Crude Oil } \\
(\%)\end{array}$ & $\begin{array}{c}\text { Serbuk Gergaji } \\
(\%)\end{array}$ & $\begin{array}{c}\text { Sludge Biogas } \\
(\%)\end{array}$ & IM \\
\hline A0 & 80 & 20 & 0 & 0 & - \\
\hline A1 & 80 & 20 & 0 & 0 & $\mathrm{IM}$ \\
\hline B0 & 50 & 20 & 10 & 20 & - \\
\hline B1 & 50 & 20 & 10 & 20 & IM \\
\hline$x_{1}$ & 50 & 20 & 20 & 10 & - \\
\hline $\mathrm{Cl}$ & 50 & 20 & 20 & 10 & IM \\
\hline Do & 30 & 20 & 30 & 20 & - \\
\hline D1 & 30 & 20 & 30 & 20 & $\mathrm{IM}$ \\
\hline E0 & 30 & 20 & 20 & 30 & - \\
\hline EI & 30 & 20 & 20 & 30 & $\mathrm{IM}$ \\
\hline Fo & 30 & 20 & 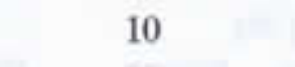 & 40 & - \\
\hline $\mathrm{F} 1$ & 30 & 20 & 10 & 40 & IM \\
\hline
\end{tabular}

Tingkat \% degradasi TPH diukur dengan rumus sebagai berikut (Ijah\&Upke, 1992 dalam [11]):

$\%$ Degradasi $=\frac{T P H_{0}-T P H_{f}}{T P H_{0}} \times 100 \%$

- $\mathrm{TPH}_{0}=\mathrm{TPH}$ hari ke- $0(\mathrm{~g})$

- $\mathrm{TPH}_{4}=$ TPH hari ke-t $(\mathrm{g})$ 


\section{Analisis Senyawa dengan GC-MS}

Analisis GC-MS Shimadzu QP 2010 ULTRA dilakukan dengan membandingkan \% area senyawa hidrokarbon yang memiliki $\%$ efisiensi degradasi TPH terbaik, yakni perlakuan E1 pada awal dan akhir bioremediasi.

\section{Aplikasi Hasil Remediasi}

Hasil Remediasi selama 90 hari ditunjukkan dengan makin menurunnya kadar TPH di dalam tanah, sehingga mengindikasikan adanya perbaikan pada lahan yang tercemar lumpur minyak. Oleh karena itu dilakukan aplikasi hasil remediasi menggunakan tanaman uji berupa rumput gajah (Pennisetion purpureum ).

\section{HASIL DANPEMBAHASAN}

Hasil pengujian dan pengamatan parameter dalam pemanfaatan serbuk gergaji sebagai campuran media berbasis kompos radiasi yang diperkaya dengan konsorsia inokulan mikroba hidrokarbonoklastik pada bioremediasi lahan tercemar lumpur minyak bumi sclama 90 hari adalah sebagai berikut :

\section{A. Pengaruh suhu pada proses bioremediasi}

Pada Gambar 1 memunjukkan bahwa bioremediasi selama 90 hari berlangsung pada suhu berkisar $26^{\circ} \mathrm{C}$ $31,7^{\circ} \mathrm{C}$. Hal ini sesuai dengan yang diperoleh Atlas et al yang menyatakan bahwa laju degradasi cemaran lumpur minyak bumi yang optimal terjadi pada suhu antara $20^{\circ} \mathrm{C}-35^{\circ} \mathrm{C}$. [2]. Suhu merupakan pengontrol pada aktivitas metabolik dari mikroorganisme karena degradasi bahan organik secara mikrobiologis terjadi melalui aktivitas enzim. Secara umum peningkatan suhu menunjukkan adanya aktivitas metabolik meningkat karena adanya lebih banyak energi dalam sistem. Aktivitas mikroba meningkat sampai sekitar $45^{\circ} \mathrm{C}$ namun melampaui suhu ini, kegiatan mikrobiologi akan menurun dan akhimya berhenti.
Aktivitas mikroba tanah terbukti menurun drastis pada suhu $10^{\circ} \mathrm{C}$ dan berhenti samasekali pada suhu $5^{\circ} \mathrm{C}$ [1]. Namun scharusnya suhu tidak menjadi masalah bagi negara - negara tropis seperti Indonesia dengan suhu lingkungan sekitar $24^{\circ} \mathrm{C}-35^{\circ} \mathrm{C}$, karena aktivitas mikroba dengan bantuan enzim dapat melakukan bioremediasi efektif hingga $50^{\circ} \mathrm{C}$. Suhu cenderung rendah karena oil sludge ditambahkan campuran media berupa serbuk gergaji dan sludge biogas serta pupuk NPK diaduk rutin dan dicampur dengan tanah bersih. Kondisi tersebut meningkatkan porositas campuran yang menyebabkan cepat hilangnya panas yang terbentuk. Sedangkan pembalikan dan pengadukan yang terlalu sering akan mempercepat penguapan air yang menyebabkan tumpukan menjadi sulit mengisolasi panas. Suhu tanah memberikan efck yang besar dalam aktivitas mikroorganisme dan laju biodegradasi. Peningkatan suhu sebesar $10^{\circ} \mathrm{C}$ dapat meningkatkan laju reaksi hingga dua kali lipat [8]. Kenaikan suhu juga akan mempengaruhi kenaikan nilai bio-transformasi dalam aktivitas mikroorganisme, kenaikan solubilitas kontaminan dan penurunan proses adsorbsi kontaminan di dalam tanah. Suhu optimum bagi hampir semua mikroorganisme tanah umumnya $0-40^{\circ} \mathrm{C}$, walaupun ada beberapa yang dapat hidup pada suhu hingga $\quad 60^{\circ} \mathrm{C}$ (bakteritermofilik). Sedangkan pada suhu rendah, proses biodegradasi akan terhenti. Pada penelitian ini baik pada composter bioremediasi ataupun composter kontrol, suhu tanah berada pada kisaran antara $260 \mathrm{C}-31,70 \mathrm{C}$ (Gambar 1). Kisaran tersebut mengindikasikan bahwa bakteri indigenous yang ada di dalam composter kontrol dan bakteri eksogenous dapat hidup pada suhu normal. Hasil statistik Anova untuk analisis suhu menunjukkan nilai signifikan $(\mathrm{P} \leq 0,05)$ dilanjutkan uji Duncan yang memperlihatkan beda nyata pengaruh campuran media (serbuk gergaji + shudge biogas) dan mikroorganisme fungsional berbasis kompos iradiasi terhadap suhu proses bioremediasi. 


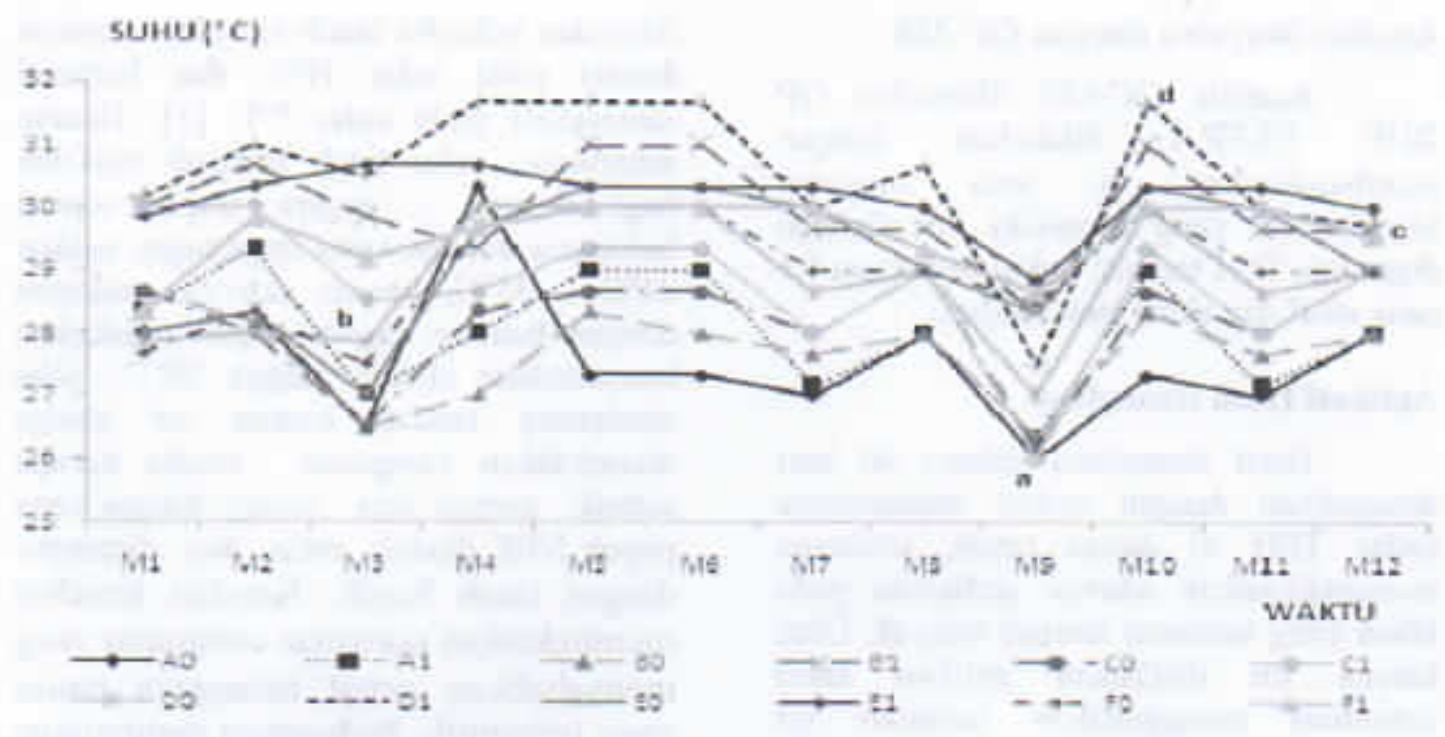

Gambar1. Pengukuran suhu pada bioremediasi lahan tercemar lumpur minyak.

B. Pengaruh pH pada proses
bioremediasi

Pada Gambar 2 ditunjukkan kondisi $\mathrm{pH}$ tanah mendekati kisaran 6,1 8,3 . Hasil pengukuran nilai $\mathrm{pH}$ selama 90 hari pengamatan menunjukkan bahwa nilai $\mathrm{pH}$ tanah tidak selalu bersifat asam. Pada hari ke-30 nilai $\mathrm{pH}$ eampuran cenderung agak asam, namun masih sesuai dalam jangkauan $\mathrm{pH}$ yang dipersyaratkan. Hal ini disebabkan adanya aktivitas mikroba menghasilkan produk pertama berupa alkohol, aldehid dan asam karboksilat [3]. Produk yang diharapkan adalah $\mathrm{CO}_{2}$ dan $\mathrm{H}_{2} \mathrm{O}$. Sedang pada hari ke-60 hingga hari ke -90 rata - rata hampir seluruh perlakuan menunjukkan torjadi peningkatan nilai $\mathrm{pH}$ hingga cenderung bersifat basa. Terjadinya peningkatan $\mathrm{pH}$ pada penelitian mikrokosmos diduga disebablan oleh adanya kemampuan bakteri dalam melakukan respon toleransi asam dengan mekanisme pompa hidrogen. Beberapa bakteri memiliki kemampuan untuk melakukan upaya homeostatis terhadap keasaman lingkungan sebatas masih dalam toleransi adaptasinya. Caranya dengan melakukan pertukaran kation $\mathrm{K}+$ dari dalam sel dan menukarnya dengan $\mathrm{H}^{+}$yang banyak terdapat di lingkungannya, schingga keasaman lingkungan dapat dikurangi [4]. Pada umumnya scmua perlakuan juga mengalami penurunan nilai $\mathrm{pH}$. Penurunan nilai $\mathrm{pH}$ tersebut diduga disebablan oleh aktivitas konsorsium bakteri yang membentuk metabolit metabolit asam. Biodegradasivalkana yang terdapat dalam minyak bumi akan membentuk alkohol dan selanjutnya męnjadi asam lemak. Asam lemak hasil degradasi alkana akan dioksidasi lebih lanjut membentuk asam asetat dan asam propionat, sehingga dapat menurunkan nilai $\mathrm{pH}$ medium [14]. Nilai $\mathrm{pH}$ tanah secara signifikan akan mempengaruhi aktivitas mikroorganisme. $\mathrm{pH}$ akan mempengaruhi reaksi transformasi biotis, kemampuan fungsi-fungsi sel, seperti tramportasi melahii mambran sed. dm kescimbangan reaksi yang takntalis oleh ervim [13]. Patumbuhan miknoorganisme alan meringkat apabila $\mathrm{pH}$ berada pada kisam 6 hingga 9 [8] Dari statistic Anova untuk analisis $\mathrm{pH}$ menunjukkan nilai signifikan $(\mathrm{P} \leq 0,05)$ dilanjutkan uji Duncan yang memperlihatkan beda nyata pengaruh campuran media (serbuk gergaji dan shudge biogas) dan mikroorganisme fungsional berbasis kompos iradiasi terhadap $\mathrm{pH}$ proses bioremediasi. 


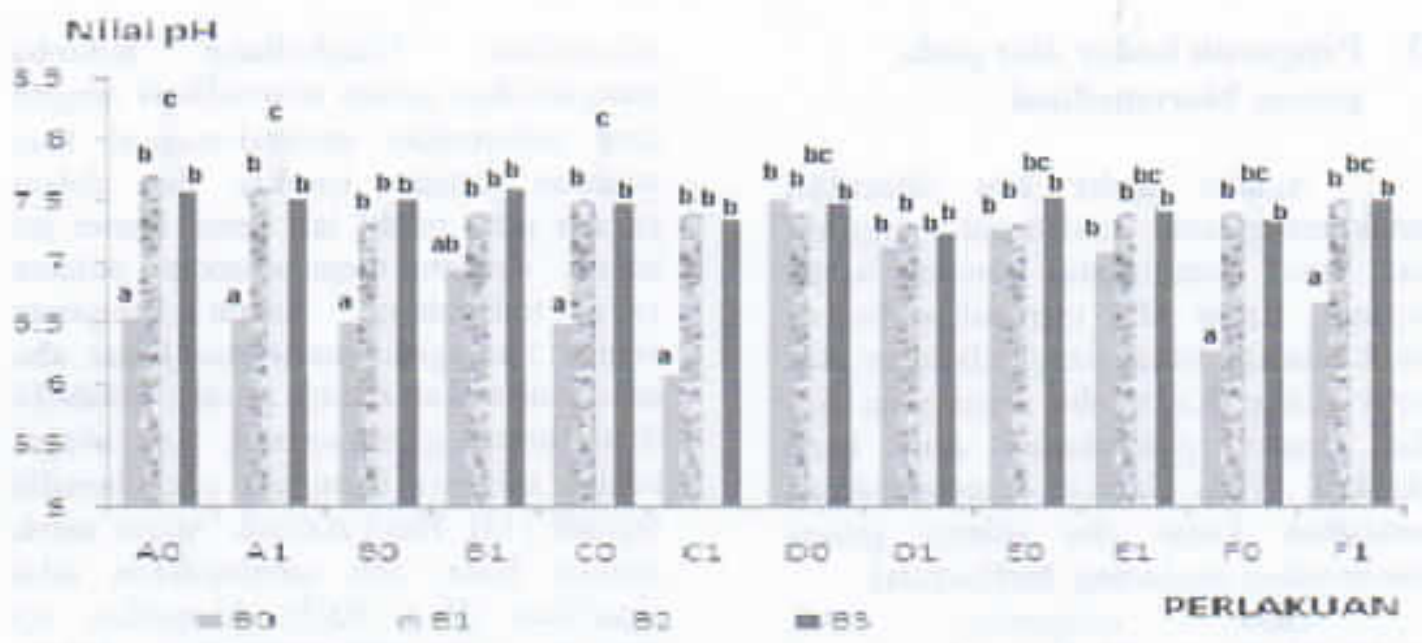

Gambar 2 Pengukuran $\mathrm{pH}$ dalam proses bioremediasi selama 90 hari

C. Pengaruh kadar air pada
bioremediasi

Kadar air sangat penting untuk hidup, tumbuh dan aktivitas metabolik mikroba. Berdasarkan pengukuran yang dilakukan setiap bulan, kadar air yang terukur berkisar antara 30,03$83,65 \%$ seperti yang tertera pada Gambar 3. Nilai yang bervariasi ini diakibatkan karena perbedaan perlakuan pada tiap sampel. Setiap minggunya dilakukan penambahan air pada sampel secara teratur. Pada proses bioremediasi hidrokarbon, kadar air merupakan faktor penting, karena diperlukan untuk aktivitas metabolik dari mikroorganisme pada limbah minyak bumi karena mikroorganisme akan hidup aktif antara interfase air dan minyak [20]. Menurut Fletcher (1992) selama bioremediasi, jika kandungan air terlalu tinggi akan berakibat sulitnya oksigen untuk masuk kedalam tanah sedangkan tanpa air mikroba tidak dapat hidup dalam limbah minyak. Hal ini terlihat pada composter $\mathrm{A} 0$, $\mathrm{Al}, \mathrm{B} 0, \mathrm{~B} 1, \mathrm{C} 0$ dan $\mathrm{Cl}$ dengan kandungan tanah bersih $50 \%-80 \%$ dan sludge biogas $10 \%-20 \%$ sebagai campuran media menyebabkan campuran tersebut terlalu padat dan kurang porositas. Kadar air yang dibutuhkan bakteri untuk metabolisme dalam mendegradasi hidro-karbon berkisar antara $30-90 \%$ [6]. Hal ini sesuai dengan kadar air pada composter D0, D1, E0, E1, F0 dan F1 yakni berkisar $41,13 \%$ - $65,84 \%$. Kondisi ini disebabkan karena pada variasi composter tersebut memiliki eampuran media dengan porositas yang baik. Bakteri yang digunakan adalah bakteri aerob, yaitu bakteri yang membutuhkan oksigen. Oksigen tersebut dapat diperoleh dari udara melalui proses pengadukan dan air. Kadar air yang terlalu tinggi akan berakibat sulitnya oksigen masuk ke dalam tanah dan penurunan kadar air dapat terjadi karena penguapan. Hasil statistik Anova untuk analisis kadar air menunjukkan nilai signifikan ( $P \leq$ $0,05)$ dilanjutkan uji Duncan yang memperlihatkan bahwa campuran media (serbuk gergaji + sludge biogas) dan mikroorganisme fungsional berbasis kompos iradiasi memberikan beda nyata pengaruh terhadap $\%$ kadar air. 


\section{Pengaruh kadar abu pada proses bioremediasi}

Analisa kadar abu dilakukan untuk mengetahui jumlah zat anorganik sisa hasil pembakaran suatu bahan organik. Kadar abu merupakan bagian berat mineral bahan yang didasarkan atas berat kering. Kadar abu merupakan sisa dari proses pembakaran atau hasil oksidasi. Pada Gambar 4 menunjukkan perubahan kadar abu selama proses bioremediasi cenderung berfluktuasi.

Pada composter A0,
$\mathrm{A} 1, \mathrm{~B} 0, \mathrm{~B} 1, \mathrm{C} 0$ dan $\mathrm{Cl}$ dengan kandungan tanah bersith $50 \%-80 \%$ sebagai campuran media, akan memiliki kandungan mineral yang lebih besar dibandingkan composter D0, D1, E0, E1, F0 dan F1. Kenaikan kadar abu disebabkan oleh adanya proses mineralisasi. Metabolisme mikroba menyebabkan proses mineralisasi dengan cara melepaskan mineral-mineral hara tanaman dengan lengkap dan dalam jumlah yang relatif tak tentu. Proses ini terjadi dengan memanfaatkan polutan yang terkandung dalam campuran media. Sedanglan penurunan kadar abu mengindikasikan adanya produk metabolit dalam bentuk garam organik atau sebagai bentuk senyawa kompleks yang bersifat organik [12]. Hasil statistik Anova untuk: analisis kadar abu menunjukkan nilai signifikan ( $\mathrm{P} \leq 0,05)$ dilanjutkan uji Duncan yang memperlihatkan bahwa campuran media (serbuk gergaji + sludge biogas) dan milkroorganisme fungsional berbasis kompos iradiasi memberikan beda nyata pengaruh terhadap \% kadar abu.

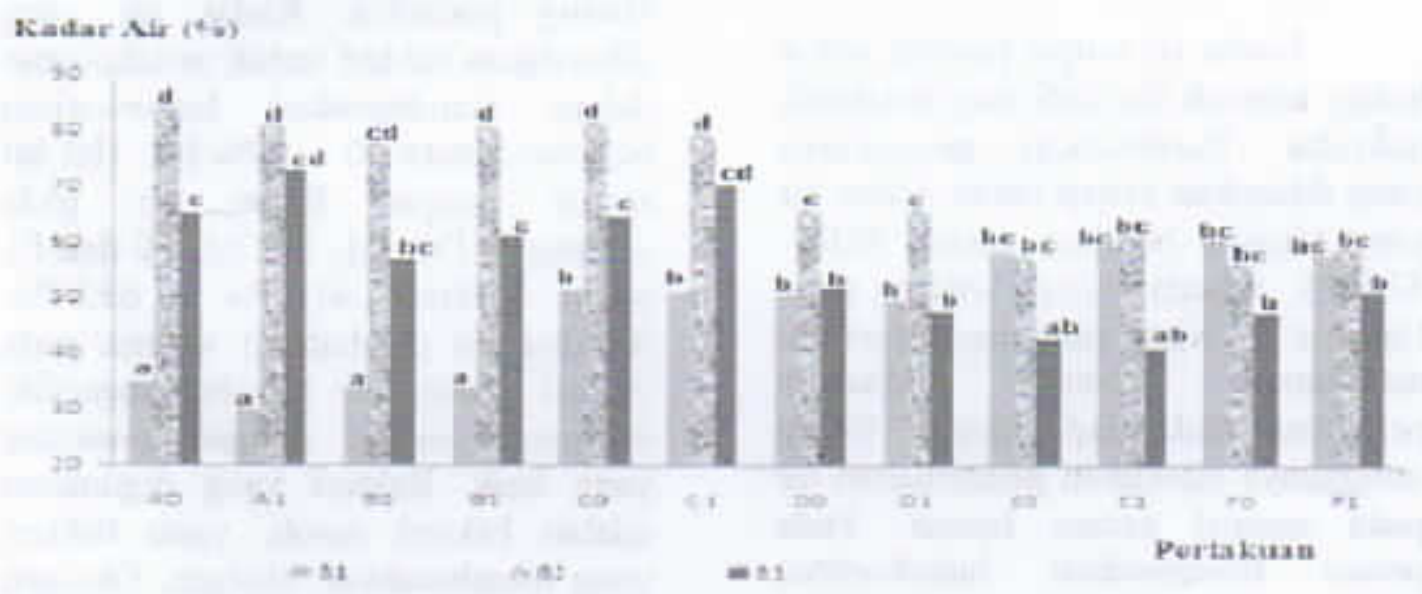

Gambar 3. Pengukuran kadar air dalam bioremediasi selama 90 hari.

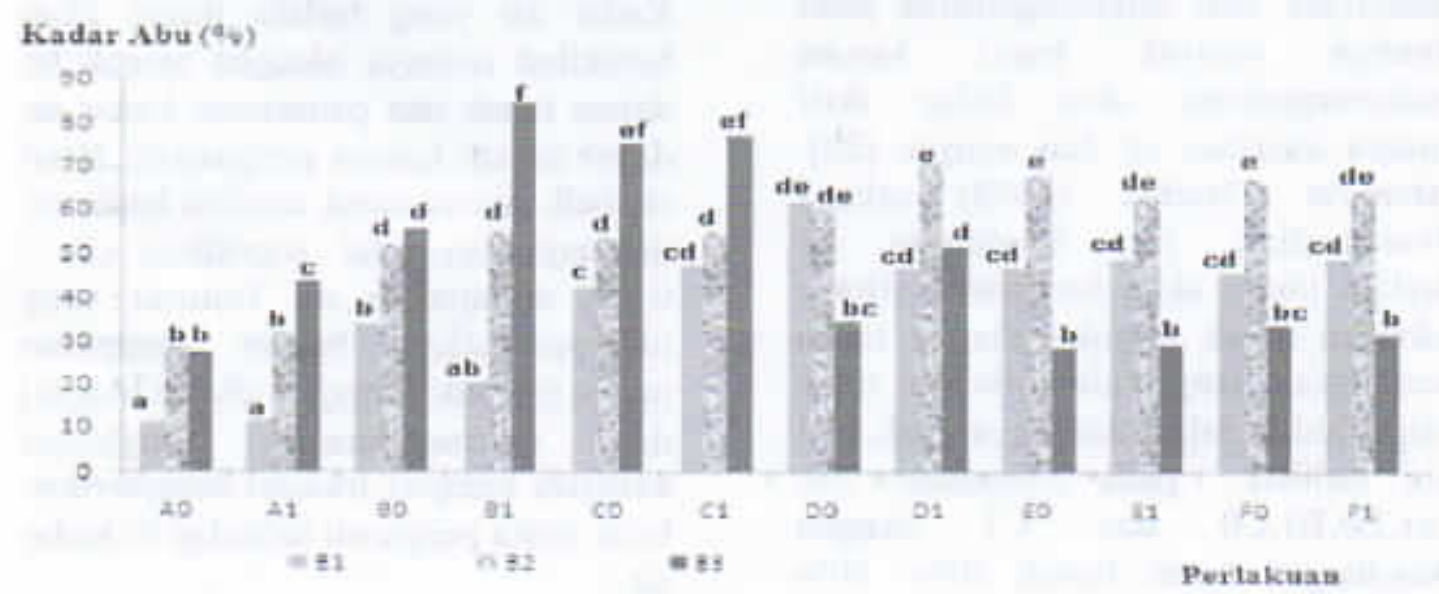

Gambar 4. Pengukuran kadar abu dalam bioremediasi selama 90 hari. 


\section{E Pengaruh kadar bahan organik pada bioremediasi.}

Bahan organik tanah merupakan salah satu bahan pembentuk agregat tanah, yang berperan sebagai bahan perekat antar partikel tanah untuk bersatu menjadi agregat tanah. Perubahan kadar bahan organik dalam sampel dapat dilihat pada Gambar 5, yang menunjukkan penurunan kadar bahan organik pada composter A0, $\mathrm{Al}, \mathrm{B} 0, \mathrm{~B} 1, \mathrm{CO}$ dan $\mathrm{Cl}$ dan peningkatan kadar bahan organik pada composter D0, D1, E0, E1, F0 dan F1. Bahan organik tanah berpengaruh terhadap peningkatan porositas tanah. Porositas tanah adalah ukuran yang menunjukkan bagian tanah yang tidak terisi oleh udara dan air. Pori dalam tanah menentukan kandungan air dan udara dalam tanah serta menentukan perbandingan komposisi udara dan air yang baik. Aerasi tanah terkait dengan $\mathrm{O}_{2}$ dalam tanah. Oleh karena itu bahan organik tanah memberikan pengaruh terhadap acrasi tanah, yang terkait dengan pernafasan mikroorganisme dalam tanah dan akar tanaman [16]. Hasil statistik Anova untuk analisis kadar bahan organik menunjukkan nilai signifikan ( $\mathrm{P} \leq 0,05$ ) dilanjutkan uji Duncan yang memperlihatkan bahwa campuran media (serbuk gergaji + shudge biogas) dan mikroorganiame fungsional berbasis kompos iradiasi memberikan beda nyata pengaruh terhadap \% kadar bahan organik.

\section{F. Degradasi Total Petroleum Hydrocarbons (TPH) pada bioremediasi}

TPH merupakan salah satu parameter penting dalam menentukan keberhasilan proses bioremediasi. Dari Gambar 6 terlihat bahwa composter E1 yakni bioremediasi sclama 60 hari memberikan $\%$ efisiensi degradasi TPH yang optimal sebesar $83,14 \%$ Composter El menggunakan campuran media berupa serbuk gergaji $20 \%$, shudge biogas $30 \%$ serta tanah $30 \%$ mampu mendegradasi hidrokarbon dalam oil shudge sebesar $20 \%$ yang diperkaya dengan konsorsium inokulan mikroba berbasis kompos radiasi.
Ini sesuai dengan hasil penelitian yang telah dilakukan sebelumnya pada pemilihan bahan campuran media dalam bioremediasi lahan terecmar lumpur minyak selama 42 hari, mendapatkan $\%$ efisiensi degradasi TPII yang optimal scbesar $81,32 \%$ menggunakan konsorsia inokulan mikroba berbasik kompos iradiasi dalam $30 \%$ serbuk gergaji pada konsentrasi tanah 50\% [19]. Susunan senyawa yang kompleks seperti minyak bumi menyebabkan suatu spesies tunggal mikroorganisme tidak dapat mendegradasi keseluruhan komponen penyusun minyak bumi tersebut, karena setiap spesies balcteri membutuhkan substrat yang spesifik Beberapa balteri yang berinteraksi saling menguntungkan dalam bentuk konsorsium sangat berperan selama berlangsungnya proses degradasi minyak bumi. Keberadaan konsorsia inokulan mikroba menghasillkan \% degradasi shudge minyak yang lebih optimal dibandingkan tanpa penambahan konsorsia inokulan mikroba. Hal ini tampak pada composter $\mathrm{CO}, \mathrm{Cl}$, D0, DI,E0, E1, F0 dan F1. Walker dan Colwel (1974, dalam [4]) menyebutkan keanekaragaman dan kelimpahan mikroorganisme pendegradasi hidrokarbon yang terdapat di alam memiliki hubungan yang linier dengan peningkatan kadar polusi hidrokarbon. Hal ini berarti konsorsium bakteri dalam variasi perlakuan ini dapat memanfaatkan siudge minyak bumi sedemikian rupa sehingga kelimpahannya semakin meningkat. Dengan demikian proses degradasi hidrokarbon berlangsung efektif yang dibuktikan dengan semakin tingginya persentase degradasi yang dihasilkan. Sedangkan composter A0, A1, B0 dan B1 menunjukkan kondisi scbaliknya, dimana composter $\mathrm{A} 0$ dan $\mathrm{B} 0$ yang tidak dipcrkaya konsorsia inokulan mikroba mampu memberikan $\%$ degradasi TPH yang lebih besar dibandingkan composter A1 dan B1. Hal tersebut disebabkan karena pemanfaatan sludge minyak bumi oleh konsorsium mikroba belum berlangsung secara efektif. Diduga kelompok bakteri yang mendominansi mikrokosmos adalah kelompok mikroba indigenous. Menurut Doerffer [7] senyawa hidrokarbon yang 
tertumpah di alam akan mengalami degradasi secara alamiah karena faktorfaktor lingkungan, meskipun laju degradasinya berlangsung lambat. Proses degradasi tersebut meliputi penguapan, teremulsi dalam air, teradsorpsi pada partikel padat, tenggelam dalam perairan serta mengalami biodegradasi oleh mikroba pengguna hidrokarbon. Suhu dapat menycbabkan terjadi penguapan hidrokabon, terutama senyawa berberat molekul rendah yang biasanya bersifat toksik [10]. Pada penelitian di laboratorium, pengocokan medium dapat berlangsung lebih efektif karena menggunakan shaker mcubator, tidak demikian dengan penelitian skala mikrokosmos. Faktor pengadukan mikrokosmos secara manual diperkirakan menyebabkan percampuran antara tanah sebagai media, sludge minyak bumi scbagai sumber polutan serta konsorsium baikteri dafam mikrokosmos kurang homogen. Oleh karena itu suplai oksigen menjadi kurang efektif. Hal ini pun dapat mempengaruhi besarnya persentase degradasi. Hasil statistik Anova untuk analisis 9 degradasi TPH menunjukkan nilai signifikan $(\mathrm{P} \leq 0,05)$ dilanjutkan uji Duncan yang memperlihatkan bahwa eampuran media (serbuk gergaji + sludge biogas) dan mikroorganisme fungsional berbasis kompos iradiasi memberikan beda nyata pengaruh terhadap \% degradasi TPH. Pada Gambar 7. Ditunjukkan pengukuran ekstraksi TPH pada hari ke -60 .

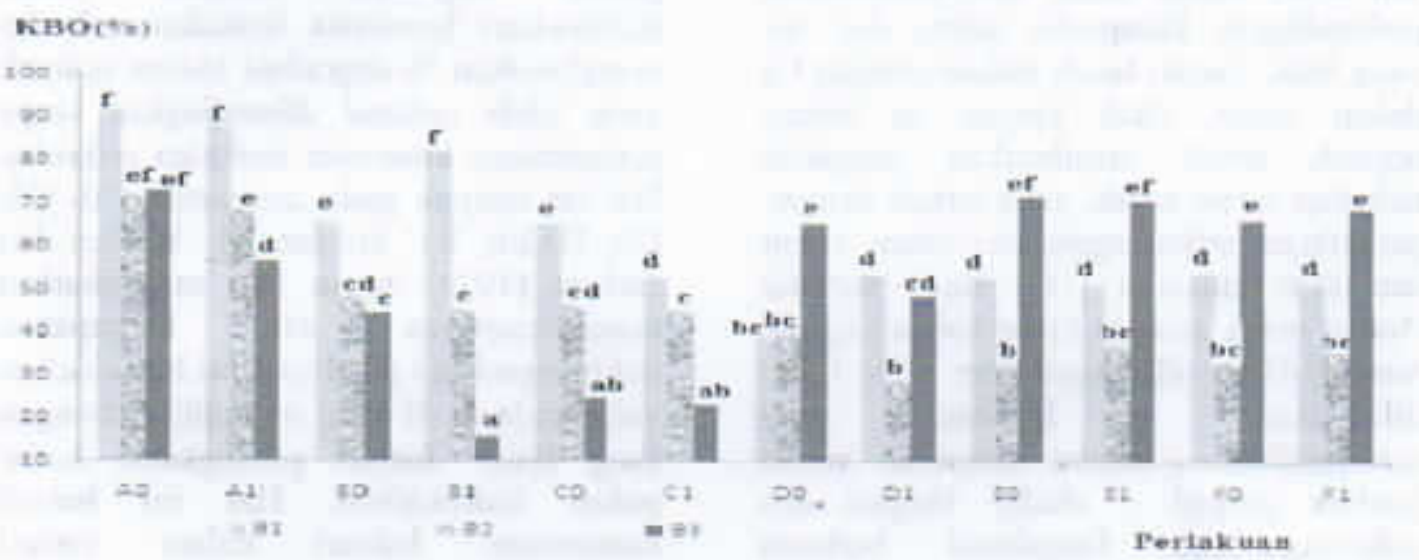

Gambar 5. Pengukuran kadar bahan organik padas bioremediasi selama 90 hari.

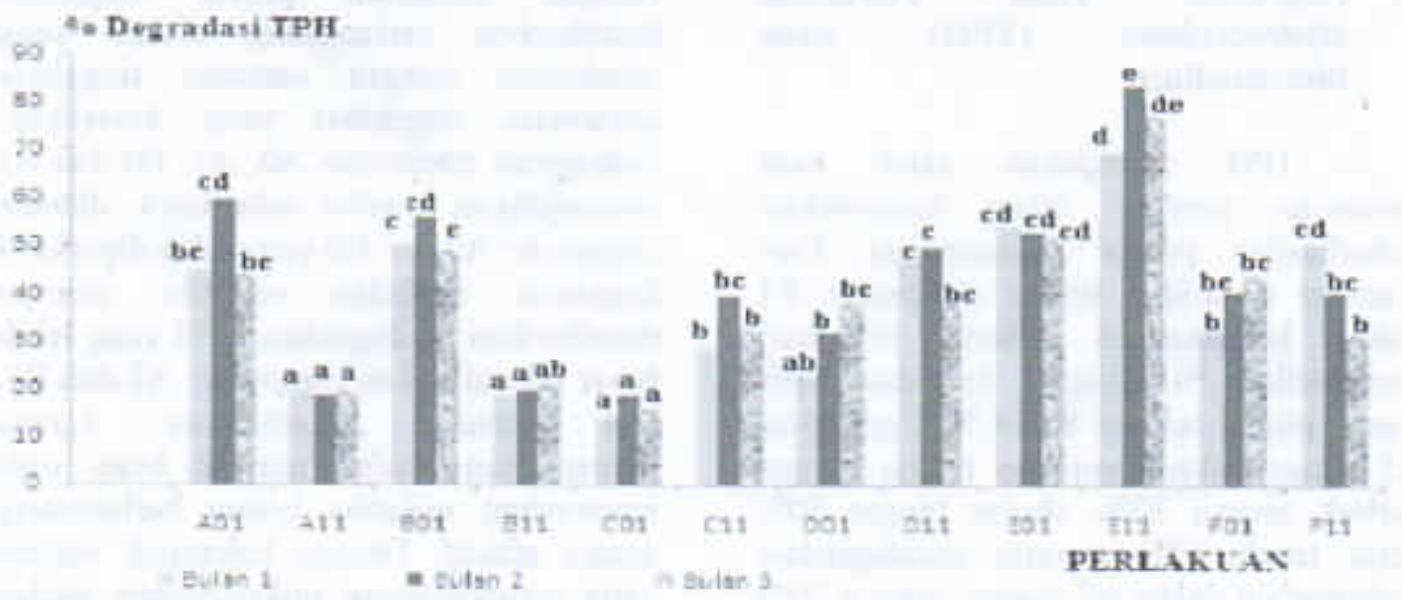

Gambar 6. Pengukuran \% degradasi TPH dalam bioremediasi selama 90 hari 


\section{G. Analisis Senyawa dengan GC-MS}

Kromatogram hasil GC-MS (Gas Chromatography- Mass Spectrofotometri) untuk perlakuan E1 kondisi awal dan akhir bioremediasi ditunjukkan pada Gambar 8 . Berdasarkan kromatogram tersebut menunjukkan bahwa pada akhir bioremediasi yakni hari ke -60 terjadi penurunan luas area puneak yang terdeteksi pada waktu tambat 1 - 30 menit dibandingkan dengan kondisi awal perlakuan (hari ke -0 ). Hal itu menunjukkan bahwa telah terjadi degradasi senyawa hidro-karbon. Pada Tabel 2 ditunjukkan kelimpahan senyawa hidrokarbon pada awal perlakuan. Pada awal periakuan $2,4,6$, 10-tetrametil heksadekana (C-20) merupakan senyawa yang memiliki \% area tertinggi sebesar 8,6 sedangkan di akhir perlakuan senyawa heksana (C-6) memiliki \% area tertinggi sebesar 88,09 . Tingginya $\%$ anea pada akhir perlakuan didnga merupakan sisa hasil degradasi dari n-alkana rantai panjang menjadi n-alkana rantai pendek.
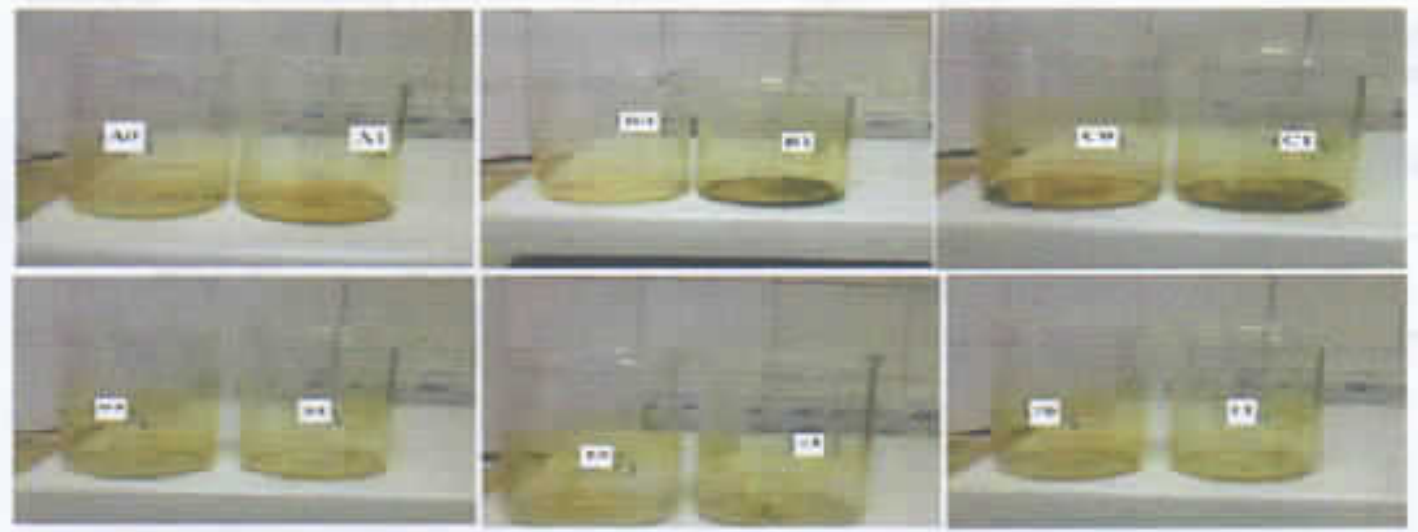

Gambar 7. Hasil ekstraksi TPH pada proses bioremediasi hari ke-60

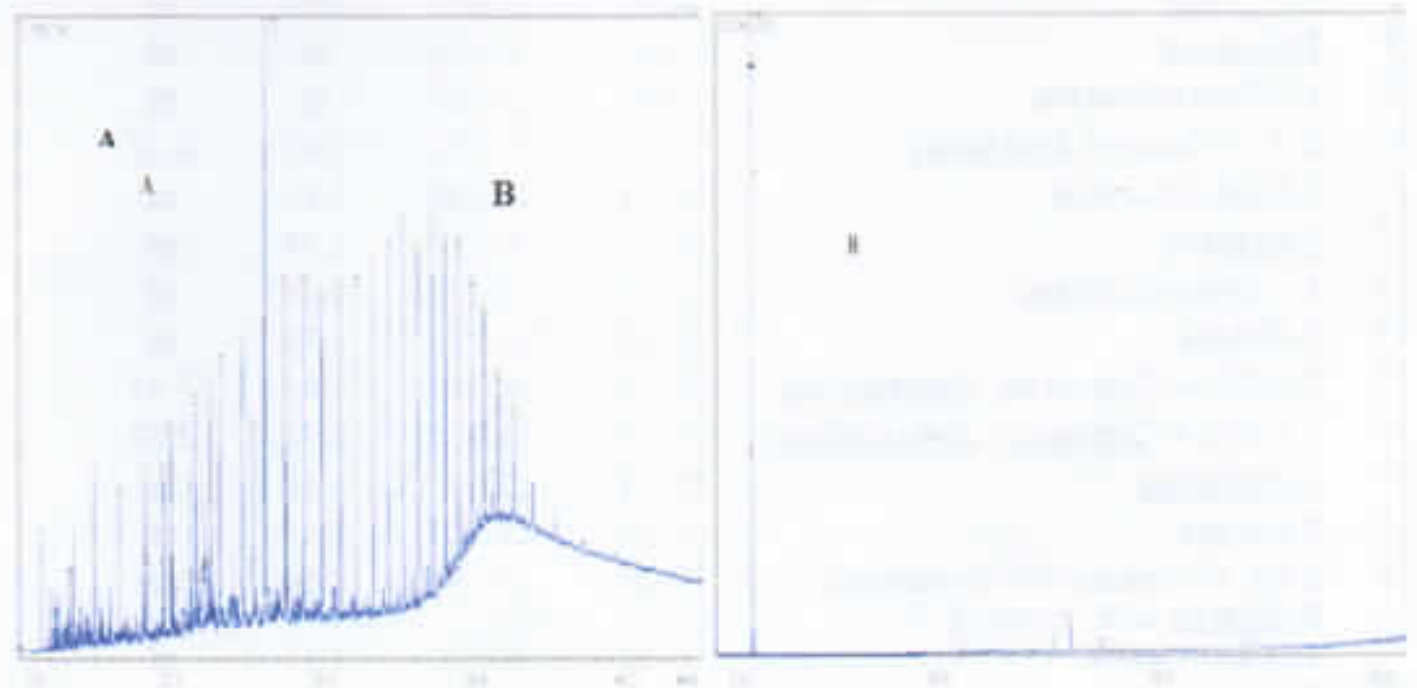

Keterangan : $\mathrm{A}=$ Kromatogram awal senyawa hidrokarbon perlakuan E1 $\mathrm{B}=$ Kromatogram akhir senyawa hidrokarbon perlakuan E1

Gambar 8. Kromatogram degradasi hidro-karbon. 


\section{H. Aplikasi hasil remediasi}

Perlakuan yang telah mengalami proses biorcmediasi secara pengomposan selama 90 hari selanjutnya diaplikasikan dengan menggunakan tanaman rumpur gajahı (Pennisetum purpurezom Schumacher) yang tahan terhadap kekeringan schingga dapat tumbuh dengan baik dalam kondisi sub-tropis. Karena tidak semua tanaman dapat digunakan dalam remediasi. karena tidak semua tanaman dapat melakukan metabolism, volatilisasi dan akumulasi polutan. Untuk menentukan tanaman yang dapat digunakan meremediasi tahan tereemar lumpur minyak, dipilih tanaman dengan karakteristik antara lain : cepat tumbuh, mampu mengkonsumsi air dalam jumlah banyak dengan waktu tumbuh yang singkat dan toleransi tinggi terhadap polutan [Youngman, 1999]. Pada Gambar 9 ditumjukkan pertumbuhan tanaman rumput gajah setelah melalui proses bioremediasi.

Selama 90 hari. Campuran media pada perlakuan kontrol $\mathrm{A} 0$ dan $\mathrm{Al}$ masih tinggi cemaran polutannya sehingga tanaman rumput tidak dapat tumbuh. Campuran media pada perlakuan E1 memberikan hasil optimal, baik tampa penambahan konsorsia mikroba fungsional maupun dengan penambahan konsorsia dapat memberikan pertumbuhan rumput gajah yang optimal.

Tabel 2. Senyawa Hidrokarbon pada awal dan akhir bioremediasi

\begin{tabular}{|c|c|c|c|c|c|}
\hline \multirow{2}{*}{ No } & \multirow{2}{*}{ Senyama Hidrakarhon } & \multirow{2}{*}{ C Ke-n } & \multirow{2}{*}{$\frac{\text { Waktu }}{\text { Retensi }}$} & \multicolumn{2}{|c|}{ 9o Area } \\
\hline & & & & Awal & Akhir \\
\hline 1 & 2-Netilpeutana & C.6 & 1.542 & $t d$ & td \\
\hline 2 & Heksank & C.6 & $: .58$ & td & $\$ 8.09$ \\
\hline 3 & Dibtila iklopentans & C.6 & 2.676 & td & 2.05 \\
\hline 4 & Detritsililobuksen & C.? & 2075 & 0.45 & td \\
\hline 5 & Satilben:2ม & C.7 & 2.333 & td & td \\
\hline 6 & 1,3-Dimetilsikloheissen & C. 3 & 2.420 & 0.43 & td \\
\hline 7 & O-Xuilens & C.8 & 3.260 & 0.60 & td \\
\hline 8 & Etulbenzen. & C.8 & 3.162 & td & td \\
\hline 9 & 1.2-Dimetilben=en & C. -8 & 3.530 & ted & td \\
\hline 10 & 2,5,10-Trmetil Dodelkanz & $c-10$ & 3.538 & 0.95 & 0.43 \\
\hline 11 & 2-Nethylnatalen & C.:1: & 10.068 & 0.81 & td \\
\hline$: 2$ & Undekana & C.11 & 6.555 & 1.39 & td \\
\hline 13 & 1,4-Dimatilnaftalen & C-12 & 12.130 & 0.91 & td \\
\hline 14 & 2-Delana & $\mathrm{C}-12$ & 8.272 & 136 & td \\
\hline 15 & 2,6,10,14- Ietrametul Pentadeliane & $\mathrm{C}-15$ & 9.998 & 1.95 & 7.34 \\
\hline 16 & $2,6,10,: 4$ - Tetrametil Helsoadikana & $\mathrm{C}-16$ & $: 1.332$ & 0.74 & 2.09 \\
\hline 17 & Qktadakan & $\mathrm{C}-18$ & $13.18^{7}$ & 2.33 & td \\
\hline 18 & Eikserana & $c-20$ & 18.724 & 3.35 & td \\
\hline 19 & $2,2,6,10$ - Ietrametilhelcsadalcma & $\mathrm{c}-20$ & 16.184 & 8.56 & td \\
\hline 20 & $\begin{array}{l}\text { Sultigrous, acid, dodfexil - } \\
\text { ethylhexylester }\end{array}$ & C. 20 & 9.512 & 1.37 & td \\
\hline $2 !$ & Hentikerana & $c-21$ & 14.675 & 2.69 & td \\
\hline 22 & Selosakseman & C. 26 & $21 .: 18$ & 3.45 & td \\
\hline 23 & Detrolkouana & C. 32 & 26.292 & 4.21 & td \\
\hline 24 & Eselssatriakentana & C.36 & 28.100 & 3.59 & td \\
\hline 25 & Tetrasentaksutang & C- -54 & $3: 549$ & 1.92 & td \\
\hline
\end{tabular}




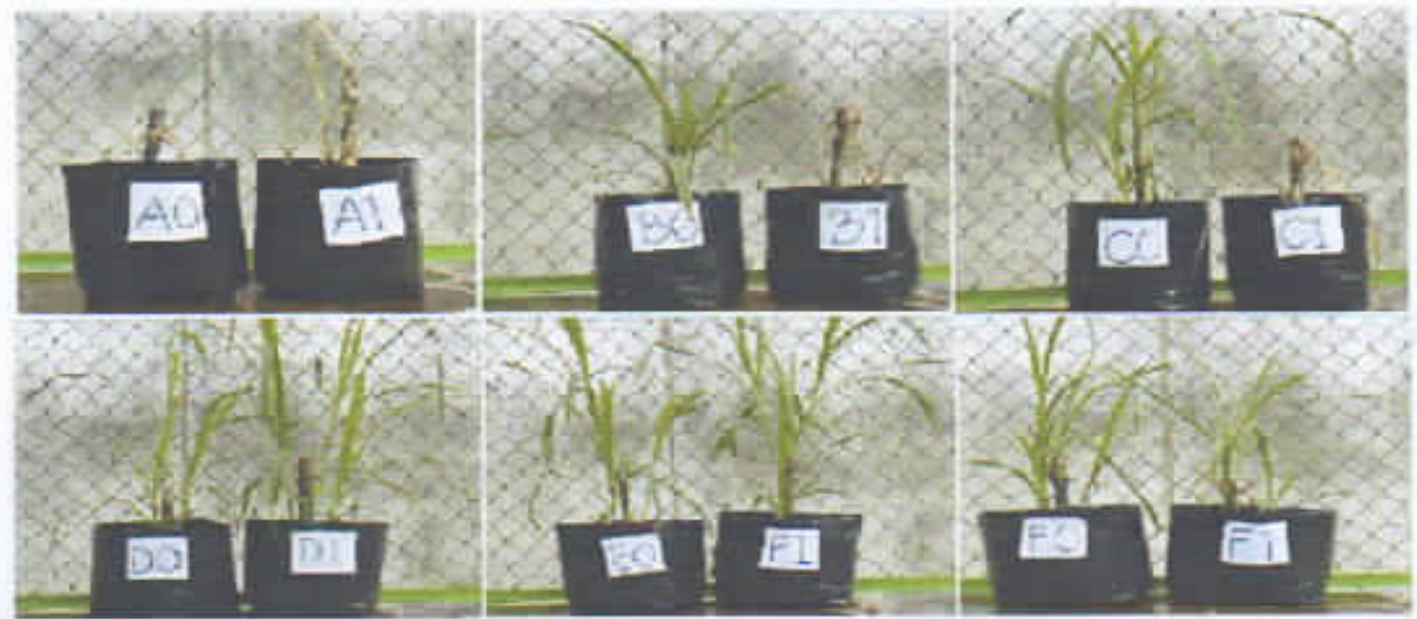

Gambar 9. Remediasi menggunakan rumput gajah (Pennisetum purpuretum)

\section{UCAPAN TERIMA KASIH}

Penulis mengucapkan terima kasih kepada Bapak Marwadi (PAIR-BATAN) atas bantuan teknis di lapangan selama penelitian ini beriangsung.

\section{KESIMPULAN}

Hasil bioremediasi lahan tercemar lumpur minyak bumi menunjukkan bahwa perlakuan E1 menggunakan campuran media optimal, yakni berupa serbuk gergaji $20 \%$ dan sludge biogas sebesar $30 \%$ serta tanah $30 \%$ dan konsonsia inokulan mikroba berbasis kompos radiasi mampu mendegradasi hidrokarbon dalam $20 \%$ otl shudge dengan efisiensi degradasi TPH scbesar $83,14 \%$ selama 60 hari .

\section{DAFTAR PUSTAKA}

Antizar-Ladislao, B., Beck, A. J., Spanova, K., Lopez-Real, J., Russell, N. J., 2007. The infuence of different tempenature programmes on the bioremediation of polycyclic aromatic hydrocarbons (PAHs) in a coal-tar contaminated soil by invessel composting. J. Hazard. Mater. $144,340-347$.
Atlas, R. M. and Berta, R. (1992). Hydrocarbon biodegradation and oil spill bioremediation, Adv. Microbial Ecol. 12 : 287 - 338.

Budihardjo M. A. 2007. Stridi Pengaruh Bulking Agents Pada Proses Bioremediasi Lampur minyak, Jurnal Purifikasi, Vol.8 N0.1, Juni $2007: 55-60$.

Chator dan Somerville, The OAl Inchistry and Microbial Ecosystems, Heyden \& Son Ltd. London, 1978.

Deacon, J. W. 1984. Introduction to Modern Mycology, London ; Blackwell Scientific Publication.

Dibble, J. T., and R. Bartha. 1979. Effect of Environmental Parameter on The Btodegradation of Soll Sludge, App. Environ. Microbial. 37 (4) : $729-739$.

Docrffer, J. W, Oil Spill Response in the Marine Environment, First Ed Pergamon Press, Tokyo.1992, p. 9-20, 91-99. $133-161$.

Eweis JB, Engas SJ, Chang EDDPY, Schoroeder. 1998. Bioremediation Principles. New York : MoGraw Hill. 
FNCA Biofertilizer Project Group, (2006), Biofertilizer Manual, Pages 41 89. Forum for Nuclear Cooperation in Asia (FNCA), Japan Atomic Industrial Forum, Tokyo.

Hirayama, S. K, Biodegradation of Crude Oil. Program and Abstracts in the First Asia - Pasific Marine Biotechnology Conference. Shimizu, Shizuoka, Japan, 1995.

Ijah U. J. J Safiyanu, H \& Abioye, O, P. 2008. Comparative Study of Biodegradation of Crude Oil in Soil Amended With Chicken Dropping and NPK Fertilizer. Sctence World Joumal Vol. 3 No. 2).

Mulyohardjo. 1998. Telnologi Penganetan Pangan. U. L. Press. Jakarta.

Notodarmojo, S. (2005). Penoemaran Tanah \& Atr Tonah, Penerbit ITB, Bandung.

Rosenberg, E., Legmann, R., Kushmaro, A. Taube, R. dan Ron, E. Z. Petroleum Bioremediation a Multiphase Problem: Biodegradation, (1992). p. 337 350.

Ryckeboer, J., Coosemans, J., Swings, J., Mergaert, J., Gestel, V. K. 2003. Btoremediation of Diesel OitContaminated Soil by Compasting with Biowaste. Environ. Poll., $125: 361-368$.

Stevenson, F. J. 1997. Kimia Pengomplekan lon Logam Dengan Organik Lanitan Tanah. Universitas Gadjah Mada Press. Yogyakarta.

Sulistyowati, A. (2001). Bioremediast Tanah Terkonteminasi Hidrokarban di PT. NNT, Tugas Akhir Teknik Lingkungan ITS, Surabaya (Tidak Dipublikasikan).

Tim Perumus Bioremodiasi BPMIGASKKKS (2003). Pedoman TataCara Pengolahan Limbah Berminyak dan Tanah Terkontammasi Minyak Bumi Secara Biologi. BPMIGASKontraktor - KKS. Kaltim : Total E \& P Indonesia.

Tri Retno D. L. Nana M. 2013. Bioremediast Lahan Tercemar Limbah Lumpur Minyak Mengsunakan Campuran Bulking Agents yang Diperkaya Konsorsia Mikroba Berbasis Kompos Iradiast, Jumal Ilmiah AIR. Vol. No. Desember 2013 : ... - ...

Udiharto, M., S. A. Rahayu, A. Haris dan Zulkifliani 1995. Peran Bakteri dalam Degradast Minak dan Pemanfaatannya dalam Penanggulangan Minyak Bumi Buangan. Proceeding Diskusi Ilmiah VIII PPTMGB. Lemigas. Jakarta. 